En cuanto a la aplicación de las enseñanzas de la etnografía a la doctrina del materialismo histórico, sólo la afecta en algún grado, en cuanto al rumbo imprimido a ella por los principales escritores marxistas quienes la han utilizado más con el propósito de afianzar una ideología que en buscar las verdaderas bases de la historia, sin prejuicios. Sin embargo, lo que sorprende es que los fundamentos mismos de la doctrina expuesta de una manera dispersa en las obras de Marx y Engels, han sufrido muy poco por las críticas y abusos a que han sido sometidos. Con ligeras modificaciones quedan firmes, a pesar del gran avance de las ciencias y de las ideas, si les quitamos todo el envoltorio de sofismos usados por los que han tratado de utilizarlos para determinados fines.

Como método, el materialismo histórico es también excelente, toda vez que se lo aplica sin prejuicios y $\sin$ la intención de valerse de el para comprobar teorías preconcebidas. Sin duda debe valerse, en todo caso de las más recientes investigaciones de la etnografía y aun de la arqueología, la que correlaciona la vida de los antiquísimos pueblos, largo tiempo desaparecidos, con los cuya historia nos es más conocida. También va sin decir que los conocimientos actuales y las interpretaciones que hoy damos a los fenómenos sociales, serán mañana caducos y habrá que renovarlos. Toda evolución, lo que hoy parece ser verdad, mañana se estima falso así que es peligroso dogmatizar y sólo se pueden presentar los hechos que se conocen al momento y las deduciones que se cree poder sacar logicamente de ellos, sin preocuparse mayormente de lo que tendrá que decir el futuro.- $R$ I C A R D O E. L A T C IH A $M$.

Santiago, Abril 30 de 1933.

\title{
«REDESCUBRIMIENTO DE DON JUAN»
}

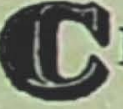

IERTOS escritores sepañoles no han podido ver con total indiferencia, que una de tlas creaciones más geniales de su literatura-Don Juan-haya sido tratada sin miramientos por plumas autorizadas.

Escritores de muy diversas tendencias como Ortega y Gasset y Pío Baroja, han puesto muy en claro, que don Juan representa algo más que el personaje clínico y el mito sexual de que nos hablan Marañón y Ramiro de Maeztu. 
Ortega y Gasset, a quien se le ha llamado el Don Juan del espíritu, y cuya afición erótica por los temas más variados, ha sido señalada por el crítico alemán Curtius; si no ha defendido al héroe sevillano en el terreno en que lo ha situado Marañón, por lo menos ha demostrado en algunas ocasiones cierta cordialidad al interpretarlo.

«Don Juan en el hombre que ante la mujer no es sino hombre; ni padre, ni marido, ni hermano, ni hijo.» (Notas, página 119).

«Don Juan es como Don Quijote, un héroe poco inteligente: posee ideas sencillas, tranquilas, retóricas, que casi no son ideas, que más bien son párrafos». («Espectador». Tomo VI, página 186).

Aunque parezca raro, es Pío Baroja, médico y novelista, uno ds los que ha situado a Don Juan en otro plano que el de la fisiología.

«Al salir de la Edad Media y al comenzar la vida moderna en las sociedades europeas se levantan en contra de la disciplina férrea, rígida, establecida por Roma a base de la Biblia y los demás artefactos de dominación semítica, tres figuras o símbolos. La figura del Norte es Fausto, el Fausto legendario luego transmutado en Hamlet. Esta figura encarna el libre examen, el intelectualismo, la teoría. La figura simbólica del Sur es Don Juan. Es la protesta de los instintos eróticos, la afirmación, sin teorías, de la libertad del placer. Entre el norte y el Sur se yergue el tipo del aventurero, del caballero andante, y su caricatura genial, Don Quijote».

«En España no contamos, quizá, con la gran representación de la figura nórdica e intelectual, aunque el Segismundo de «La vida es sueño» tiene mucho de ella. El protagonista del «Diablo mundo", de Espronceda, es también, aunque en menor escala, de la familia fáustica. Si ese símbolo nórdico del libre examen, Fausto-Hamlet no tiene gran encarnación entre nosotros, las otras dos figuras transcendentales, Don Juan y Don Quijote, son genuinamente españoles». (Conferencia en un Cine-Club).

En realidad hasta ahora se ha prestado demasiada importancia a la carne de Don Juan y muy poca a su esencia y espíritu, o como dice Royo-Billanova y Morales:

«Todo lo más que han hecho, la fisiología, la anatomía y patalogía médicas, al aplicarse en el estudio de Don Juan, es penetrar más o menos profundamente en el cuerpo de su espíritu hecho carne, pero no en su alma mismas.

El libro de este autor constituye una defensa de Don Juan, y parece haber sido hecha por un abogado y no por un médico. 
Defensa cálida, llena de frases brillantes y entusiastas, aunque no siempre convincentes. No analiza a su personaje, sencillamente lo defiende, porque está íntimamente convencido de su significado y de su valor simbólico.

Si los enemigos de Don Juan hablan de «complejos de inferioridad», de afeminamiento, de insuficiencia viril, Royo Villanova nos habla de «voluntad de poder», de «superhombre nietzscheano de representación nacional, etc.

$\mathrm{El}$ autor hace un interesante recuento de todos los Don Juanes que ha aparecido en la historia. Registra un Don Juan sanguinario como Barba Azul, un Don Juan prosaico como Landrú, un Don Juan vulgar, como los seductores de las comisarías y de los juzgados de guardia. Un Don Juan médico, el que el autor ha estudiado en su libro: "Los médicos don Juanes» (Villadolid, Librería Santarén, 1931).

El Don Juan afeminado y dudoso de los salones, los donjuanes nouveauxriches. Ultimamente han aparecido en todo el mundo dos nuevos tipos de Don Juan: el Don Juan deportivo de estadio o de "ring» y el Don Juan de cine. Ahora-anota el autorcon la concesión del voto a las mujeres, surge unanueva modalidad: el donjuanismo político. Pronto tendremos el Don Juan radical, el socialista, el demócrata y el anarco-sindicalista.

Royo-Villanova acepta la defensa de Don Juan en todos sus aspectos, exceptuando uno solo, el mismo en el que lo ataca de preferencia Marañón.

«Lo supremamente importante en la figura de Don Juan es su ser esencial y lo más despreciable es su sintomatología donjuanesca, sobre todo la de orden clínico. Su vida privada se halla realmente desprovista de interés. En cambio la vida espiritual de su gran espíritu es el símbolo de todo nuestro pueblo.» (página 53).

«El triunfo de Don Juan es el triunfo más humano, porque es un triunfo del orgullo. Es el instinto de Yó (Nietzsche); es la voluntad de poderío (Jung, Adler) y esta fuerza constituye la rúbrica personal de todos sus gestos». (página 129).

A ratos las páginas del médico español parecen leídas en una asamblea:

*Don Juan es nuestro, es de España, es español, el más genuinamente español de todos los españoles. Si no fuera enemigo de las fórmulas y de las definiciones, yo lo definiría diciendo que es el precipitado psicológico del espíritu nacional; el átomo más importante de nuestro inconsciente colectivo; la fórmula abreviada-abreviadísima-de nuestra apariencia social; el compuesto... etc., etc. 
Royo-Villanova dice y grita, rara vez analiza o discute. Su trabajo es casi un alegato producido por la indignación. Sin embargo y por eso mismo, su libro es ameno y hay en el muchos aciertos.

«Don Juan, como toda leyenda poética, tiene una fuerza popular enorme, indestructible, porque es la primera figura mística, histórica, que encauza con fuerza indestructible la aspiración del hombre». (página 23).

"Todos los donjuanes extranjeros, no son, no podrán ser nunca descendientes directos-y, en cierto sentido, ni aún indirectos - del verdadero Don Juan, que - volvemos a repetires genuinamente y fundamentalmente español». (página 12).

«La mujer española, sometida a las suceptibilidades de la intriga mediterránea, se consume en la espera del amor aventurero y en el temor-que ardientemente desea-del drama fatal que ha de seguir». (página 127).

«El pecado capital, específico del verdadero Don Juan, no es pues la vanidad, sino el orgullo, ya que no distingue entre la "princesa altiva» y "la que pesca en ruin barca». (página 129).

«En los tiempos que ahora corren, hay que reconocer que Don Juan, todos o por lo menos la mayoría de los donjuanes, sólo pueden tener éxito en España, donde la mujer se encuentra en un lamentable estado de educación sexual». (página 123).

En este "Redescubrimiento .... se defiende a Don Juan con más intención de dejarlo bien puesto que de descubrir su esencia. Sin embargo la posición del autor es mucho más ancha y total que la de otros escritores españoles que han tomado al ilustre personaje sólo en sus momentos más ingratos.

$Y$ aún cuando las mejores plumas de la Península tratan de canjear sus ideas y su historia por ideas e historia europeas, siempre las habrá más modestas que defendiendo lo nacional, con poco mérito, a todo trance, y aún con argumentos aparentemente pobres y antojadizos, estén mucho más cerca de la verdad de su tierra. Don Juan, personaje español, tienen su verdad española, y sólo una ciudad en que caben íntegras sus mejores aventuras, su castigo y su muerte: Sevilla. Don Juan es Sevilla y Sevilla Don Juan. Ya lo dice el poeta granadino Federico García Lorca:

$$
\begin{aligned}
& \text { Y loca de horizonte } \\
& \text { mezcla en su vino } \\
& \text { lo amargo de Don Juan } \\
& \text { y lo perfecto de Dionisio } \\
& \text { (Sevilla, «Canciones»). }
\end{aligned}
$$


Anotemos de paso que no siempre parece conveniente analizar creaciones literarias con instrumental clínico. Nos quedaríamos con que los tres grandes personajes españoles-Don Quijote, Don Juan y la Celestina-caen en los terrenos de la Psiquiatría y aún de la policía. Por otra parte nuede servir de advertencia la opinión de Isidoro Fernández Flores:

«El día, en que anunciándose «Don Juan Tenorio», estén vacíos los teatros, quizá España haya llegado a su completa civilización, pero ya no será España».

Un poco de respeto y simpatía para Don Juan, jugador y hombre de azar. Don Juan, que puede estar en un garito español pero que también pudo encontrarse en una carabela de los Pinzones, o haciendose amar en lejanas tierras descubiertas, por indias portadoras de una nueva raza.- J U A N U R I B E ECHE V A R R Í A. 